\title{
Laboratory techniques in the investigation of human papillomavirus infection
}

Ethel-Michele de Villiers

\section{Introduction}

Although the existence of a human papillomavirus was demonstrated by electronmicroscopy as early as $1949,{ }^{1}$ the plurality of this group of viruses only became evident about 30 years later. ${ }^{23} \mathrm{With}$ the advent of gene technology, methods to clone and characterise the viral DNA became available, the result of which is a list to date totalling 68 different genotypes of known human papillomaviruses, with probably a number of yet to be identified types still to come.

\section{Plurality of the human papillomaviruses}

After the recognition of the existence of different types of human papillomaviruses (HPV), Orth et $a l^{3}$ demonstrated the presence of different HPVs in lesions of patients suffering from epidermodysplasia verruciformis. Here a number of different HPV types can occur in lesions from the same patient, sometimes even more than one type within one lesion. Table 1 presents a very generalised summary of papillomaviruses detected in skin lesions (benign and malignant).

The association of a papillomavirus infection with the development of genital carcinoma was postulated by zur Hausen. ${ }^{4}$ The rapid progress in papillomavirus research, as well as the development of methods to detect an HPV infection, have largely been influenced by this association. Not only have 27 different HPV types been isolated from benign and malignant genital lesions (table 2), but the various aspects of the hypothesis been investigated and verified on a molecular [zur Hausen, in press] and epidemiological ${ }^{5}$ level. Although the available data can only serve as an indication (table 3), ${ }^{6}$ papillomaviruses will most probably be shown to play an important etiological role in the development of the majority of benign and malignant tumours of the oral mucosa, as well as in head and neck tumours.

Table $1 \quad H P V$ types present in skin lesions

Referenzzentrum für Humanpathogene Papillomviren, Deutsches Krebsforschungszentrum, Im Neuenheimer Feld 506, 6900 Heidelberg, Federal Republic of Germany E-M de Villiers

Accepted for publication 30 September 1991

\section{The papillomavirus genome}

The genome of a papillomavirus consists of a number of open reading frames (ORF), each capable of coding for a messenger RNA which in turn will be translated into a protein. These ORFs are grouped into those coding for proteins active in the nucleus and cytoplasm of the host cell (early proteins), and those coding for viral capsid proteins (late proteins), the $\mathrm{L} 1$ and $\mathrm{L} 2$. The L1 ORF contains sequences conserved in all papillomaviruses and codes for a group specific antigen. ${ }^{78}$ The L2 polypeptide has been suggested to be the type specific antigen, but such sequences have not yet been identified unequivocally amongst those HPV DNAs sequenced. The E1 has, at least in the bovine papillomavirus, been identified as the gene responsible for the replication and maintenance of the episomal form of the DNA molecule within the host cell. ${ }^{910}$ The E2 controls the transcription rate of the other early genes, ${ }^{1112}$ such as the E6 and the E7, both of which are known as the genes playing a major role in the malignant transformation of a host cell. ${ }^{13}$ The function of the E4 gene has not been fully understood. The E4 gene product can be detected within the cytoplasmic inclusion granules of papillomatous lesions ${ }^{14}$ and probably acts by binding and disrupting certain cytokeratins. ${ }^{15}$ The functions of the other ORFs in the HPV genome have not yet been clarified.

The transcription patterns of the ORFs have been studied in great detail. ${ }^{1617}$ The localisation of the single mRNAs has been demonstrated in genital lesions varying from condyloma acuminata, low grade CIN to high grade CIN to invasive carcinomas. ${ }^{18}$ The detection of such transcripts could be of inportance in the diagnosis of a lesion, that is, which grade in the development of malig-

Table 2 HPV types present in genital lesions

\begin{tabular}{ll}
\hline Condylomata acuminata & $6,11,42,44,51,55,(53), 67$ \\
Intraepithelial neoplasia & $6,11,16,18,30,31,33,34$, \\
& $35,39,40,42,43,45,51,52$, \\
& $56,57,59,61,62,64$ \\
Carcinoma & $6,11,16,18,31,33,35,39$, \\
& $45,51,52,54,56,66$ \\
\hline
\end{tabular}

Table 3 HPV types present in tumours of the head and Table
neck

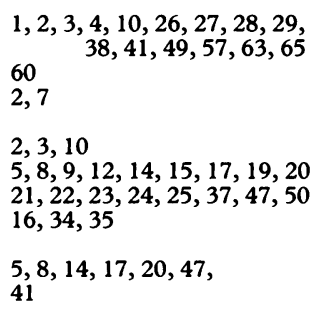

\begin{tabular}{ll}
\hline Papillomatoses & $6,11,32$ \\
& $7,57(2)$ \\
$\begin{array}{l}\text { Focal epithelial } \\
\text { hyperplasia }\end{array}$ & 13,32 \\
Carcinoma & $2,6,11,16,18,30$ \\
\hline
\end{tabular}


nancy. Another factor of increasing importance in the diagnosis is whether the viral DNA exists as an episomal molecule or whether it is integrated into the cellular genome, in which case the E2 ORF is usually disrupted. ${ }^{16}$ The HPV genome is in an episomal state in benign and premalignant genital lesions, but integrated in the majority of invasive carcinomas. ${ }^{19-21}$

\section{Definition of an HPV type}

Papillomaviruses need a differentiating cell layer for the circular double-stranded DNA molecule to replicate and the capsid proteins to be synthesised and assembled to form mature virus capsids. Owing to these special requirements, papillomaviruses cannot be cultivated in the laboratory on a routine basis. Therefore the methods applied to detect a papillomavirus infection have had to be varied from the usual serological detection methods used in other viral infections, to nucleic acid detection. Only lately the use of serological diagnostic methods can be envisaged.

The definition of a papillomavirus type has been based on the degree of DNA sequence homology to other known papillomaviruses. ${ }^{22}$ These comparisons have in the past been conducted through hybridisation in liquid phase between the DNA genomes of two papillomaviruses. If the homology was higher than $50 \%$, the newly isolated clone was regarded as a subtype of the known papillomavirus. If the homology was lower than $50 \%$, it was classified as a new type. The degree of DNA homology between different HPVs varies considerably. Some types are very closely related such as HPV 6, HPV 11, HPV 13 and HPV 55 , many of the viruses isolated from epidermodysplasia verruciformis lesions, HPV 5, HPV 8, HPV 12, HPV 19-23, HPV 25, HPV 47 and HPV 50. Others show almost no degree of homology to any of the known types, for example HPV 41. It has become quite evident that the present form of classification is very unsatisfactory. With the increasing number of complete DNA sequences of different HPV types becoming available and more unknown HPV types being isolated and characterised, the possibility of a reclassification of the HPVs is in sight. The present definition of a new type is based on less than $90 \%$ sequence homology in the ORFs E6, E7 and $\mathrm{L} 1$ to any other known HPV type.

\section{Methods to detect an HPV infection}

At present, each of the techniques generally used to detect any papillomavirus infection has its advantages, as well as disadvantages. They vary greatly in sensitivity and in specificity. None of the tests can be labelled as the ideal method to be used as a diagnostic tool, but, as long as the question to be answered is well defined, and seen within the limitations of the test used, any of the following methods can be used. A crucial necessity in the interpretation of results obtained with any test, is the inclusion of adequate controls throughout.

\section{Antigen detection}

The papillomavirus group-specific antigen ${ }^{7}$ can be detected using commercially available tests. Only highly differentiated cells containing large numbers of viral particles will stain positive, indicating that only lesions in which viral capsids are being produced, will be seen as HPV positive. This is misleading in so far as the majority of lesions induced by, for example, HPV 1 will be seen as positive, whereas lesions containing, for example, HPV 16, will hardly be detected. The different types apparently differ in the frequency with which mature virus particles are being produced. By detecting the group-specific antigen, no distinction can be made as to which type is involved in the infection.

\section{Serology}

The production of individual viral proteins has to be executed with the help of bacterial and other expression systems. This is a procedure which has been delaying progress not only in the development of serological tests, but in the use of antibodies directed against proteins from individual HPV ORFs to detect infection on histological sections. Problems still exist as to whether the antibodies studied are really typespecific. Only a limited number of HPV types are at the moment being included. Although no serological tests to be used routinely are at present available, the situation is due to change in the foreseeable future.

\section{Methods of hybridisation}

The methods most commonly used at present, all involve the principle of nucleic acid hybridisation. Hybridisation means, in very simple terms, that two single stranded fragments of nucleic acid (either DNA or RNA or both) will, under the experimental conditions provided, attach to each other like a perfect zipper if they originate from a mutual parent molecule (high stringency), or imperfect (that is, with intermittant loops of discordance) if homology exists only in certain segments of the fragment in question. In the latter, hybridisation conditions can be varied according to the purpose involved. The DNA sequences of HPV 6 and HPV 11 share such a high degree of homology that they will cross-hybridise even under conditions of high stringency. In contrast, HPV 41 DNA will hybridise to any other HPV DNA only if the conditions are such that duplexes will form at all inspite of numerous mismatches. Such a form of hybridisation is, in contrast to high-stringency hybridisation, very unstable and can easily be reversed. In order to detect any of these hybridisation products, one of the single strands involved ("probe") is either radio-labelled or labelled with a product which can be made visible by additional enzymatic reactions. The non-labelled singlestranded nucleic acid molecule to be tested, is usually fixed to a solid phase.

\section{Probes}

To avoid false positive results, the HPV DNA used as labelled probe, should always be separated from the vector used in its produc- 
tion. The latter could hybridise to sequences present in bacteria possibly contaminating the lesion under investigation. The DNA or RNA probe can be labelled using one of the following methods:

(1) Nick-translation: ${ }^{23}$ with the help of DNase, "gaps" are introduced into the double-stranded DNA into which new DNA strands are synthesised with DNA polymerase I incorporating labelled nucleotides. The specific activity of the resulting probe depends on the number and activity of the labelled nucleotides being incorporated.

(2) Random-primer synthesis: ${ }^{24}$ a random pool of hexanucleotides, being annealed to the DNA molecule, act as primers for the enzymatic synthesis of new DNA strands containing the labelled nucleotides. As this can be repeated several times, the resulting DNA probe not only spans the length of the input DNA molecule, but the specific activity of the probe can be higher than obtained when using nicktranslation.

In both these methods the DNA molecules are melted into single strands before being added to the hybridisation solution.

(3) Synthesis of single-stranded RNA probes: ${ }^{25}$ HPV DNA, cloned into a plasmid vector carrying bacteriophage RNA polymerase binding sites, is transcribed into labelled virus-specific single-stranded RNA molecules after addition of RNA polymerase and the appropriate labelled nucleotides. Such a probe is free of contaminating bacterial sequences and the specific activity obtained is very high.

(4) Polymerase chain reaction (PCR):26 27 The PCR can also be used to synthesise labelled probes consisting of short nucleotide sequences. Although the resulting labelling can be extremely high and very specific, oligonucleotides are usually 17 to 20 nucleotides in length requiring a modification of regularly used hybridisation conditions to assure specific annealing. ${ }^{28}$

New methods for labelling probes, using non-radioactive substances, are constantly being investigated and developed: kits for HPV detection via chemiluminiscense will probably be available in the near future.

\section{In situ hydridisation}

Tissue sections are treated to obtain singlestranded DNA molecules. Although the morphology of the tissue can be distinguished after hybridisation and the signal can be located within one cell, the sensitivity of this method is rather low. Using a radio-labelled probe, one cell has to contain at least 20 to 50 DNA genome copies to induce a visible signal upon hybridisation, ${ }^{29}$ whereas the sensitivity decreases to 350 genome copies or more per cell using non-radioactive probes. ${ }^{3031}$

The question whether a distinction can be made between two closely related HPV types present in the same lesion if the probes are identically labelled, remains controversial. ${ }^{32}$ Ways to detect double or multiple infections will in future be possible with the use of different labelling/detection systems. Although this can at present be done with, for example, digoxigenin- versus biotin-labelled probes, large differences in sensitivity (the latter 10-fold less sensitive), as well as undesired background staining should be taken into account. ${ }^{33}$ Other newly recognised advantages of this method is the distinction between integrated molecules (signal localised within the nucleus) versus episomalDNA molecules (diffuse hybridization signal over the entire cell). ${ }^{34-36}$ Another advantage is the detection of the RNA transcripts of the individual ORFs of an HPV genome. The exact localisation of these individual transcripts can help in the diagnosis of the grade of a lesion. ${ }^{8}$

\section{Filter in situ hybridisation ${ }^{37}$}

Cells obtained from a scraping or lavage, are filtered onto a membrane, denatured in situ and hybridised to a labelled probe. Although thousands of samples can be tested with relative ease, this advantage is overruled by the many disadvantages of this method. These are: -very low sensitivity (only $50 \mathrm{HPV}$ genome copies per cell or more can be detected),

-high background combined with non-specific hybridisation, in many cases due to contaminating bacteria or blood and mucous present in the sample,

- the extremely strong dependence of HPV detection on the manner in which the clinical sample was taken (surface area, number and nature of cells, blood and mucus present),

- the limitation of number of HPV types which can be applied as probes,

-owing to resulting background, non-radioactive probes cannot be used,

-adequate controls are neither available nor can these be imitated in vitro, because the constitution of smears differs between each individual patient.

\section{Southern blot hybridisation ${ }^{38}$}

For routine diagnostic purposes this method is too time consuming and labour intensive, although it can be regarded as the test from which the most information can be obtained. Cellular DNA is cut with selected restriction enzyme(s) and electrophoretically separated on an agarose gel. After denaturation, the DNA is transferred and fixed to a membrane. The latter is then hybridised with a labelled HPV probe. The sensitivity ranges between 0,1 and $0,01 \mathrm{HPV}$ genome copies per cell, depending on the amount of cellular DNA and specific activity of the probe. Questions such as episomal/ integrated, deletions, HPV type involved in the single or even double infections, relatedness of one HPV type to another, detection of unknown HPV types and presence of bacterial infection can all be answered in the minimum number of experiments through the critical choice of hybridisation conditions and probes.

\section{Reverse blot hybridisation ${ }^{39}$}

Essentially this method is similar to the usual Southern blot hybridisation, with the difference that here the individual HPV types are digested from the vector sequences and these samples then electrophoresed on an agarose gel. After 
denaturation and transfer to a membrane, hybridisation follows using radio-labelled total cellular DNA $(1 \mu \mathrm{g})$. The number and range of HPV types present on such a blot, that is, tested for in one experiment, can be varied according to the problem posed. If one of these HPV types is present in the sample tested, a positive signal will be seen in the ca. $8 \mathrm{~kb}$ fragment of the specific type. If the HPV type is representative of a group of closely related HPVs, this result could be confirmed with a subsequent Southern blot using the HPV type in question as probe. The advantage of this method is that, with an input of the minimum amount of DNA, only one experiment is needed to test for as large a number of HPV types as wished. The sensitivity is $5 \mathrm{HPV}$ genome copies per cell using nylon membrane and a radio-labelled probe. An additional advantage is the detection of contaminating bacterial sequences in the sample-the vector DNA present on the blot will give a positive signal. Only stringent hybridisation conditions can be used, owing to the fact that the genomes of several of the HPV types cross-hybridise to cellular DNA sequences under relaxed experimental conditions. The specific genome sections/ORFs of the HPVs which share these homologous sequences, vary from type to type, rendering a general rule impossible [de Villiers, Kyono, Silverstein, Delius and zur Hausen, unpublished results].

\section{Dot/slot hybridisation}

This method differs from the two preceeding in that the DNA to be fixed onto the membrane, is not electrophoretically separated, but fixed as a "dot" (drop) or "slot" (manifold used). Many of the commercial kits available make use of this method. Upon evaluating the results, no estimation can be made on the degree of nonspecific hybridisation, therefore adequate controls should be run parallel together with probes chosen which would not contain contaminating vector sequences.

\section{Polymerase chain reaction ${ }^{26} 27$}

The PCR is rapidly becoming the most frequently used technique in demonstrating an HPV infection. With the use of selected primers, a certain genome segment is amplified through ca. 30-40 cycles of denaturation/ annealing/amplification with a temperature resistant DNA polymerase. Owing to the extremely high sensitivity of this method (one HPV genome copy in 100000 cells), experimental conditions have to be very tightly controlled to rule out contamination and therefore false positive results. This contamination could occur at any stage, even as early as the moment the sample is being taken from the patient. Several possibilities to avoid the possibility of contamination have been introduced, such as the boiling of samples to exclude a step of DNA extraction. ${ }^{40}$ The most generally used primers are chosen in the L1 ORF of the HPV genome. ${ }^{41}{ }^{42}$ These primers are seen as consensus primers with which a large spectrum of HPV types can be identified. After the amplification has been done, the resulting sam- ple is separated by gelectrophoresis. Important in avoiding a false interpretation of the endproduct, is to separate the amplified DNA by gelectrophoresis, with subsequent hybridisation to type specific HPV probes, or that the amplification samples are digested with restriction enzymes to result in type specific fragment sizes. Problems can occur if the L1 ORF is deleted in a tumour in which the HPV DNA has been integrated. This is often the case in carcinomas. ${ }^{16}$ For this reason, the use of primers in the E6 ORF ${ }^{43}$ or E7 ORF ${ }^{42}$ might be advisable, even though the range of HPV types detectable might be restricted. Irrespective of which primers are being used, a percentage of the probes could still be uninterpretable $e^{45}$ or designated as "new HPV types". ${ }^{416}$ The latter could only be accepted if these "HPV types" would be isolated and characterised as a full length DNA genome. Regarding the short time interval in which this method has been available, as well as the many influencing factors, even, for example type of fixative used or fixation time, ${ }^{47}$ it is not surprising that the present state of the HPV detection rate using the PCR is fairly confusing. Time and experience is needed to sort out the facts. The use of the PCR will probably expand in future. For example methods are being developed to amplify the DNA in the intact cells of a histological section (Nuovo, personal communication). By doing this the localisation of the amplified DNA could be determined within the context of intact cellular morphology.

\section{Comparisons}

Many investigators have recently used two or more of the above mentioned methods on the same samples to compare sensitivity and specificity. As mentioned previously, each test can be used, provided the user is aware of its limitations, positive or negative. A mistake with confusing consequences is the division of clinical samples before comparing different methods. If, for example, a biopsy is divided and the separate sections tested individually, completely different results can be obtained. One area of the lesion could contain HPV DNA and the other not. Similarly, if the same instruments are applied to take more than one biopsy, a carry-over of viral DNA/particles could occur between biopsies.

\section{The value of HPV detection}

Several studies have been conducted to determine the prevalence rate of genital HPV infection in healthy individuals. A negative result obtained from one sample is not necessarily indicative of the absence of an HPV infection. Again, apart from the many varying handling and experimental conditions, a physiological variation can be detected. Multiple sampling of one women within a time span, results in the fluctuation between positivity and negativity [de Villiers et al, in press]. Although the ultimate proof has not yet been obtained, indications are that the HPV infections persist as latent infections, with intermittent cycles of 
replication or viral production. No drug is yet available to succesfully treat or remove these subclinical infections. Therefore, unless a clinical lesion or abnormal cytology has in addition been diagnosed, the detection of an HPV infection should at the present time not be of much consequence. Good evidence exists especially at the molecular biological [zur Hausen, in press] and epidemiological levels ${ }^{548}$ indicating that an HPV infection alone is not sufficient for the development of a malignant lesion, but that additional host cell modifications are needed for the cascade of events required for malignant conversion. This may be mediated by endogenous as well as by exogenous additional factors.

1 Strauss MJ, Shaw EW, Bunting $\mathrm{H}$, Melnick JL. "Crystalline" virus-like paricles from skin papillomas characterized by intranuclear inclusion bodies. Proc Soc Exp Biol Med 1949;72:46.

2 Gissmann L, zur Hausen $H$. Human papillomavirus: Physical mapping and genetic heterogeneity. Proc Natl Acad Sci USA 1976;73:1310-3.

3 Orth G, Jablonska S, Favre M, Croissant O, JarzabekChorzelska M, Rzesa G. Characterization of two types of human papillomaviruses in lesions of epidermodysplasia verruciformis. Proc Nat Acad Sci USA 1978;87:8170-4.

4 zur Hausen $\mathrm{H}$. Condylomata acuminata and human genital cancer. Cancer Res 1976;36:794.

5 Ley C, Bauer HM, Reingold A, Schiffman MH, Chambers JC, Tashiro CJ, Manos MM. Determinants of genital human papillomavirus infection in young women. $J$ Nat human papillomavirus infection

6 de Villiers E-M. Viruses in cancers of the head and neck. In: Bearing of Basic Research on Clinical Otolaryngology. Pfaltz CR, Arnold W, Kleinsasser O, eds. Adv Otorhinolaryngol 1991;46:116-23.

7 Jenson AB, Rosenthal JD, Olson C, Pass F, Lancaster WD, Shah K. Human papillomavirus: frequency and distribution in plantar and common warts. Lab Invest 1980;47:491-7.

8 Kurman RJ, Jenson AB, Lancaster, WD. Papillomavirus infection of the cervix. II. Relationship to intraepithelial neoplasia based on the presence of specific viral structural neoplasia based on the presence of specific

9 Lusky M, Botchan MR. Characterization of the bovine papillomavirus plasmid maintenance sequences. Cell papillomavirus pl

10 Lusky $M$, Botchan MR. Genetic analysis of bovine papillomavirus type 1 trans-acting replication factors. $J$ Virol 1985;53:955-65.

11 Spalholz BA, Yang Y-C, Howley PM. Transactivation of bovine papillomavirus transcriptional regulatory element by the E2 gene product. Cell 1985;42:183-91.

12 Lambert PF, Spalholz BA, Howley PM. A transcriptional repressor encoded by BPV-1 shares common carboxyterminal domain with the E2 transactivator. Cell 1987; 50:69-78.

13 Crook T, Morgenstein JP, Crawford L, Banks L. Continued expression of HPV 16 E7 protein is required for maintenance of the transformed phenotype of cells cotransformed ance of the transformed phenotype of cells cotransfo

14 Doorbar J, Coneron I, Gallimore PH. Sequence divergence yet conserved physical characteristics among the E4 proteins of cutaneous human papillomaviruses. Virology $1989 ; 172 \cdot 51-62$

15 Doorbar J, Ely S, Sterling J, McLean C, Crawford L. Specific interaction between HPV-16 E1-E4 and cytokeratins results in collapse of the epithelial cell intermediate filament network. Nature 1991;352:824-7.

16 Schwarz E, Freese UK, Gissmann L, Mayer W, Roggenbuck B, Stremlau A, zur Hausen H. Structure and transcripton of human papillomavirus sequences in cervical carcinoma cells. Nature 1985;314:111-4.

17 Yee C, Krishnan-Hewlett Z, Baker CC, Schlegel R, Howley $\mathrm{PM}$. Presence and expression of human papillomavirus sequences in human cervical carcinoma cell lines. $\mathrm{Am} \mathrm{J}$ Pathol 1985;119:361-6.

18 Stoler MH, Rhodes CR, Whitbeck A, Chow LT, Broker TR. Gene expression of HPV types 16 and 18 in cervical neoplasia. In PM Howley and TR Broker, eds. Papillomaviruses. Wiley-Liss, Inc., 1990;1-11.

19 Dürst M, Kleinheinz A, Hotz M, Gissmann L. The physical state of human papillomavirus type $16 \mathrm{DNA}$ in benign and malignant genital tumors. J Gen Virol 1985;66:1515-22.

20 Matsukura T, Koi S, Sugase M. Both episomal and integrated forms of human papilomavirus type 16 are involved in invasive cervical cancers. Virology 1989; 172:63-72.

21 Cullen AP, Reid R, Campion M, Lorincz AT. Analysis of the physical state of different human papillomavirus DNAs in intraepithelial and invasive cervical neoplasm. $J$ Virol 1991;65:606-612.

22 Coggin JR, zur Hausen $H$. Workshop on papillomaviruses and cancer. Cancer Res 1979;39:545-6.
23 Rigby RWJ, Dieckmann M, Rhodes C, Berg P. Labelling deoxyribonucleic acid to high specific activity in vitro by nick translation with DNA polymerase I. J Mol Biol 1977;113:237-51.

24 Feinberg FP, Vogelstein B. A technique for radiolabelling DNA restriction endonuclease fragments to high specific activity. Anal Biochem 1983;132:6-13.

25 Melton DA, Krieg PA, Rebagliati MR, Maniatis T, Zimm $\mathrm{K}$, Green MR. Efficient in vitro synthesis of biologically active RNA and RNA hybridization probes from plasmids active RNA and RNA hybridization probes from plasmids containing a bacte

26 Mullis KB, Faloona FA. Specific synthesis of DNA in vitro via a polymerase-catalyzed chain reaction. Method Enzymol 1987;155:335-50.

27 Saiki RK, Gelfand DH, Stoffel S, et al. Primer-directed enzymatic amplification of DNA with a thermostabile DNA polymerase. Science 1988;239:487-91.

28 Sambrook J, Fritsch EF, Maniatis T. Molecular Cloning. $A$ Laboratory Manual. Cold Spring Harbor, Cold Spring Harbor Laboratory Press, 1989.

29 Schneider A, Meinhardt G, Kirchmayr R, Schneider V. Prevalence of human papillomavirus genomes in tissues from the lower genital tract as detected by molecular in situ hybridization. Int J Gynecol Pathol 1991;10:1-14.

30 Beckmann AM, Myerson D. Diagnosis of human papillomavirus and human cytomegalovirus by hybridization histochemistry. In: Tenover FC, ed. DNA Probes for Infectious Diseases. Boca Raton, CRC Press, 1989;145-62.

31 Crum CP, Nuovo G, Griedman D, Silverstein SV. A comparison of biotin and isotope-labeled ribonucleic acid probes for in situ detection of HPV 16 ribonucleic acid in genital precancers. Lab Invest 1988;58:354-9.

32 Herrington CS, Graham AK, Flannery DM, Burns J, McGee JO. Discrimination of closely homologous HPV types by nonisotopic in situ hybridization: definition and
derivation of tissue melting temperatures. Histochem $J$ 1991;22:545-54.

33 Morris RG, Arends MJ, Bishop PE, Sizer K, Duvall E, Bird CC. Sensitivity of digoxigenin and biotin labelled probes for detection of human papillomavirus by in situ hybridiazation. J Clin Pathol 1990;43:800-5.

34 Park JS, Kurman RJ, Kessis TD, Shah KV. Comparison of peroxidase-labeled DNA probes with radioactive RNA probes for detection of human papillomaviruses by in situ hybridization in paraffin sections. Mod Pathol 1991;4: $81-5$.

35 Cooper K, Herrington CS, Graham AK, Evans MF, McGee JO. In situ evidence for HPV 16, 18, 33 integration in cervical squamous cell cancer in Britain and South Africa. J Clin Pathol 1991;44:406-9.

36 Wolber RA, Clement PB. In situ DNA hybridization of cervical small cell carcinoma and adenocarcinoma using biotin-labeled human papillomavirus probes. Mod Pathol 1991;4:96-100.

37 Wagner D, Ikenberg H, Bohm N, Gissmann L. Identification of human papillomavirus in cervical swabs by deoxyribonucleic acid in situ hybridization. Obstet Gynecol 1984;64:767-72.

38 Southern EM. Detection of specific sequences among DNA fragments separated by gel electrophoresis. J Mol Bio 1975;98:503-17.

39 de Villiers E-M, Schneider A, Gross G, zur Hausen H. Analysis of benign and malignant urogenital tumors for human papillomavirus infection by labelling cellular DNA. Med Microbiol Immunol 1986;174:281-6.

40 van den Brule AL, Meijer CJ, Bakels V, Kenemans P, Walboomers J. Rapid detection of human papillomavirus in cervical scrapes by combined general primer-mediated and type-specific polymerase chain reaction. $J$ Clin Microbiol 1990;28:2739-43.

41 Bauer HM, Ting Y, Greer CE, et al. Genital human papillomavirus infection in female university students as determined by a PCR-based method. JAMA 1991; 265:472-7.

42 Snijders PJF, van den Brule AJC, Schrijnemakers HF Snow G, Meijer CJLM, Walboomers JMM. The use of general primers in the polymerase chain reaction permits the detection of a broad spectrum of human papillomavirus genotypes. J Gen Virol 1990;71:173-81.

43 Yoshikawa H, Kawana T, Kitagawa K, Mizuno M, Yoshikura $\mathbf{H}$, Iwamoto $A$. Detection and typing of multiple genital human papillomaviruses by DNA amplification with consensus primers. Jpn J Cancer Res 1991;82:524-31. 44 Cornelissen MT, van dan Tweel JG, Struyk AHB, Jebbink MF, Briet M, van der Noordaa J, ter Schegget J. MF, Briet M, van der Noordaa J, ter Schegget J. Localization of human papillomavirus type 16 DNA using the polymerase chain reaction in the cervix uteri of women with cervical

45 Gravitt P, Hakenworth A, Stoerker J. A direct comparison of methods proposed for use in widespread screening of human papillomavirus infections. Mol Cell Probes 1991 5:65-72.

46 Fujinaga $Y$, Shimada M, Okazawa K, Fukushima M, Kato I, Fujinaga $\mathrm{K}$. Simultaneous detection and typing of genital human papillomavirus DNA using polymerase chain reaction. J Gen Virol 1991;72:1039-44.

47 Greer CE, Peterson SL, Kiviat NB, Manos MM. PCR amplification from paraffin-embedded tissues. Effects of fixative and fixation time. Am J Clin Pathol 1991;95: 117-24.

48 Kjaer SK, Engholm G, Teisen C, et al. Risk factors for cervical human papillomavirus and herpes simplex virus infections in Greenland and Denmark: $A$ populationbased study. Am J Epidermiol 1990;131:669-82. 